\title{
PARAPLEGIA
}

\section{Index to volume 18 (1980)}

\section{Subject index}

\section{Appliances}

Lower extremity bracing in paraplegia-a follow-up study, by Coghlan 25

Stair climbing and ability to work for paraplegics with complete lesions, by McAdam and Natvig 197

\section{Arteriovenous malformations}

Paraplegia following surgery in Foix and Alajouanine syndrome, by Kneisley et al. 33

\section{Assessment tests}

University of Miami neuro-spinal index (UMNI): a quantitative method for determining spinal cord function, by Klose et al. 330

\section{Autonomic nervous system}

Incidence and clinical features of autonomic dysreflexia in patients with spinal cord injury, by Lindan et al. 285

\section{Beds}

Kinetic nursing for acute spinal cord injury patients, by Green et al. I8I

\section{Children}

Acute spinal-cord lesions in a pediatric population: epidemiological and clinical features, by Kewalramani et al. 206

\section{Diagnostic errors}

Misdiagnosis of spinal cord injuries-the physiatrist's point of view, by Ohry et al. I5

\section{Diaphragmatic paralysis}

Unilateral diaphragmatic paralysis in spinal cord injury patients, by Carter 267

\section{Diving accidents-see Water sports in- juries}

\section{Ejaculation}

Severe hypertension in patients with high spinal cord lesions undergoing electro- ejaculation-management with prostaglandin E2, by Frankel and Mathias 293

\section{Electric stimulation}

The alternation of paraplegic patients muscle properties due to electrical stimulation exercising, by Turk et al. 386

Experimental evaluation of the urethral response to section of the spinal cord or cauda equina and to the electrostimulation of the bladder in non-human primates, by Murnaghan et al. 246

Epidemiology—see also Water sports injuries

Acute spinal-cord lesions in a pediatric population: epidemiological and clinical features, by Kewalramani et al. 206

Spinal cord injury by falls: comparison between suicidal and accidental cases, by Girard et al. $38 \mathrm{I}$

\section{Follow-up studies}

Lower extremity bracing in Paraplegia-a follow-up study, by Coghlan et al. 25

Post-clinical follow-up of spinal patients through domestic check-ups (Koblenz model), by Lang et al. I40

Recovery of spinal cord function, by Bedbrook 3 I 5

Stair climbing and ability to work for paraplegics with complete lesions-a sixteenyear follow-up, by McAdam and Natvig I97

\section{Fracture reduction}

Dorso-lumbar spine fractures: recumbent vs. operative treatment, by Jacobs et.al. 358

Guttmann, Sir Ludwig

Tribute, by Ross and Harris I53

\section{Hypertension}

Severe hypertension in patients with high spinal cord lesions undergoing electroejaculation-management with prostaglandin E2, by Frankel and Mathias 293 


\section{Hypoparathyroidism}

Thyroid hypofunction in spinal cord injury patients, by Prakash et al. 56

\section{Kinetic nursing}

Kinetic nursing for acute spinal cord injury patients, by Green et al. I8I

\section{Lumbosacral injuries}

Dorso-lumbar spine fractures: recumbent vs. operative treatment, by Jacobs et al. 358

Lumbo-sacral spinal cord injuries, by Jesel et al. $35 \mathrm{I}$

\section{Metabolism}

Free amino acid excretion in tetraplegic patients, by Claus-Walker and Rodriguez I67

\section{Muscles}

The alternation of paraplegic patients muscle properties due to electrical stimulation exercising, by Turk et al. 386

The flexion reflex as a diagnostic tool, by Pool 392

\section{Neurogenic bladder}

Clinical and urodynamic assessment of alphaadrenolytic therapy in patients with neurogenic bladder function, by Hachen 229

Dissolution of vesical calculi with renacidin in a paraplegic man, by Woodside and Crawford 69

Elongation of the active anterior wall of the uro-genital pelvic diaphragm, a late unusual complication of paraplegia, by Jurascheck et al. 24I

Experimental evaluation of the urethral response to section of the spinal cord or cauda equina and to the electrostimulation of the bladder in non-human primates, by Murnaghan et al. 246

Hydrodynamic aspects of bladder-outlet obstruction: consequences of functional micturition disorders, by Madersbacher et al. 307

The neuropathic urethra, by Gibbon et al. 22 I

Oxybutynin chloride (Ditropan) clinical uses and limitations, by Brooks and Braf 64

Urodynamic evaluation: periurethral striated EMG versus perianal striated EMG, by Perkash 275

\section{Neurological sequelae}

The prognosis of patients sustaining severe cervical spine injury $\left(\mathrm{C}_{2}-\mathrm{C}_{7}\right.$ inclusive), by Harris et al. 324

Recovery of spinal cord function, by Bedbrook 315
Survey of the neurological evolution of 300 spinal cord injuries seen within 24 hours after injury, by Philippi et al. 337

The treatment and the neurological aspects of diving accidents in Israel, by Melamed and Ohry $\quad 127$

\section{Occupational injuries}

Spinal cord lesions due to water sports and occupations: our experience in 20 years, by Gaspar and Silva 106

\section{Osteoporosis}

Zinc and osteoporosis in patients with spinal cord injury, by Ohry et al. $\quad$ I 74

\section{Pressure sores}

Pre-ischiatic silicone implants, by Castro Sierra et al; 52

Pressure sore prevention for the wheelchairbound spinal injury patients, by FergusonPell et al. 42

The tensor fasciae latae flap and its use in the closure of trochanteric and ischial pressure sores, by McGregor and Buchan 301

\section{Prognosis}

The prognosis of patients sustaining severe cervical spine injury ( $\mathrm{C}_{2}-\mathrm{C}_{7}$ inclusive), by Harris et al. 324

\section{Psychological reactions}

Coping and adaptation following acute spinal cord injury: a theoretical analysis, by Bracken and Shepherd 74

Study of psychological aspects of Egyptian paraplegic patients, by Hamza et al. I39

\section{Respiration}

Effect of swimming on increasing of cardiorespiratory capacity in paraplegics, by Pachalski and Mekarski 190

Lung volumes and mechanics of breathing in tetraplegics, by Forner 258

\section{Road accidents}

Spinal cord lesions due to water sports and occupations: our experience in 20 years, by Gaspar and Silva $\quad$ IO6

\section{Thromboembolism}

Experience with the management of deep vein thrombosis in patients with spinal cord injury. Part II: a critical evaluation of the anticoagulant therapy, by Perkash 2

The value of the thromboelastogram as means of monitoring the sub-cutaneous preventive action of calcium heparinate, by Dollfus et al. $\mathbf{I} 57$ 